\title{
FUENTES DE INFORMACIÓN Y RECURSOS DE UTILIDAD PARA EL ESTUDIO E INVESTIGACIÓN DE LA EMBLEMÁTICA
}

\author{
INFORMATION SOURCES AND USEFUL RESOURCES FOR THE STUDY \\ AND RESEARCH OF EMBLEMATICS.
}

Sagrario López Poza

Universidade da Coruña

ABSTRACT: This study provides a list of sources and resources available for the study and research of emblem books and other materials produced by emblematic culture (15th-18th centuries), with a special focus on the contributions that have been produced in recent years with the widespread use of the Internet, both in terms of primary and secondary sources, as well as electronic resources (digital libraries, databases, digital editions with text encoding inner markup, search engines, specialized portals, etc.).

KEYWORDS: Emblematics, Emblems, Imprese, Devices, Hieroglyphs, Resources for Emblem Studies.

RESUMEN: Este trabajo ofrece una relación de fuentes y recursos disponibles para el estudio y la investigación de los libros de emblemas y otros materiales producidos por la cultura emblemática (siglos XV-XVIII), poniendo especial interés en las aportaciones que se han producido en los últimos años con la generalización del uso de Internet, tanto en lo relativo a fuentes primarias como secundarias y recursos electrónicos (bibliotecas digitales, bases de datos, publicaciones con marcación, buscadores, portales especializados, etc.).

PALABRAS CLAVE: Emblemática, emblemas, empresas, divisas, jeroglíficos, recursos para el estudio de la Emblemática. 
El estudio de los libros de emblemas, la cultura emblemática de los siglos XV-XVIII y las diversas creaciones conceptuales híbridas que reúnen palabra e imagen (divisas, empresas, jeroglíficos, etc.) expresadas mediante diferentes vías de comunicación y en diversidad de soportes ha atraído desde hace unos veinticinco años el interés de una variedad de especialistas en diversas disciplinas académicas. La atención trasciende el propio estudio de las obras como género editorial, literario o artístico en sí, pues su conocimiento arroja luz también para una mejor comprensión de otras creaciones artísticas que se resisten a ser entendidas cabalmente pasados cuatrocientos o quinientos años y habiendo perdido en el camino las claves fundamentales para su interpretación.

Los libros de emblemas existen como un género editorial desde 1531, con la publicación del Emblematum liber de Andrea Alciato y su inmediato éxito ${ }^{1}$, que impulsó a otros humanistas a emularlo a lo largo de más de dos siglos, lo que nos dejó una producción ingente, estimada e influyente. En The Union Catalogue of Emblem Books ${ }^{2}$, Peter Daly y sus colaboradores tienen registrados más de 6.500 obras de emblemática e imprese en todas las lenguas europeas. Además de los libros, no hay que olvidar las muchas manifestaciones emblemáticas en la cultura material: pintura y retrato, pinturas en techos o paredes de edificios, piezas de mayólica, tapices y elementos de artes decorativas, affixiones empleadas en la fiesta pública, mucho más difíciles de estimar, dado su carácter más efímero y los avatares de guerras, inundaciones e incendios que han destruido una buena parte de esas reliquias del pasado.

Para adquirir un buen conocimiento de las Emblemática, resulta imprescindible leer y ver libros de emblemas o empresas, frecuentar los repertorios de símbolos, enciclopedias de figuraciones alegóricas, así como fuentes manuscritas que incluyen dibujos o reproducciones de divisas, con frecuencia vinculadas con los blasones heráldicos de caballeros (López Poza: 2008 y 2012). Resultan de extraordinario interés las relaciones de sucesos festivos donde se describen empresas personales ostentadas en torneos, justas o entradas solemnes en ciudades, con la inestimable explicación del relacionero que nos ayuda a comprender el sentido, nos desvela la forma y lugar donde se ostentaban y otros detalles de importancia que de ningún modo podríamos resolver sin su ayuda. Igualmente es preciso un buen conocimiento de la bibliografía secundaria (estudios sobre emblemática) que con tanta intensidad se ha producido en los últimos años. Y no podemos olvidar la lectura atenta de los tratados de preceptiva que, escritos a menudo en fechas posteriores al apogeo del proceso de creación, ofrecen importantes datos y reflexiones para comprender el complejo mecanismo creativo y de difusión.

Hace veinte años todavía se encontraban muchas dificultades para tener acceso a todas esas fuentes. Los libros no se habían editado modernamente, y los originales yacían en estantes de bibliotecas de fondo antiguo, con restricciones de consulta o en conventos e instituciones eclesiásticas con dificultades de acceso y sin facilidades de reprografía. Algunas de las obras son extremadamente raras, y para consultarlas había que viajar a donde se hallara el - a veces - único ejemplar que se conocía. Si se conseguía una copia en microfilm, se requería disponer de un lector-reproductor adecuado para poder realizar una copia en papel y estudiar la obra. Suponiendo que el investigador perteneciera a una universidad,

1. Hasta fines del siglo XVII se produjeron 171 ediciones de la obra que inició el género en 1531 (Emblematum liber de Andrea Alciato) no solo en latín, sino en francés, alemán, italiano, español e inglés. Véase: Andreas Alciatus, 1, 1985; Tung, 1989; Heckscher, 1989.

2. Proyecto descrito brevemente por Peter M. Daly, 1988. 
Fuentes de información y recursos de utilidad para el estudio e investigación de la Emblemática

no resultaba fácil convencer a quienes gestionaban las bibliotecas para que realizaran un gasto considerable en fuentes secundarias precisas para estudiar los emblemas: catálogos, obras de referencia, la revista publicada en New York Emblematica (que se edita desde 1986) y que es extremadamente cara, o para que adquirieran la colección (o parte de ella) de libros de emblemas europeos editados de forma facsimilar como los de la Emblematisches Cabinet (Georg Olms) o la colección Continental Emblem Books de la editorial inglesa The Scolar Press. Otra posibilidad era adquirir las microfichas que comercializa la editorial holandesa IDC en la colección Emblem Books, pero en ellas sólo está una parte de las obras españolas, y comprar la colección entera suponía un gasto muy elevado. El desafío era tan grande que realmente había que tener mucho tesón y una gran afición para salvar estas dificultades. Por fortuna, en pocos años se ha producido una revolución espectacular en el acceso a las fuentes primarias y secundarias gracias al uso generalizado de Internet y a proyectos de investigación subvencionados por organismos estatales, comunitarios o supraestatales. Hoy existen varios grupos en Europa, Estados Unidos y Canadá que han logrado un gran avance en el conocimiento de esta importante manifestación cultural.

Algunas de las fuentes principales para mantenerse informado sobre el estado del estudio de la cultura emblemática son las sociedades científicas que reúnen a investigadores sobre el tema.

Cada tres años The Society for Emblem Studies, celebra un encuentro internacional donde se exponen las líneas últimas en la investigación sobre Emblemática. Pueden consultar en la página web de esta asociación los lugares donde se han celebrado los congresos y los títulos de las actas: <http:// www.emblemstudies.org/>. El primer en- cuentro fue en 1987 y el número 10 se ha celebrado en Kiel (Alemania) en julio de 2014. Nuestro grupo de la Universidade da Coruña (SIELAE <http://www.bidiso.es/sielae/>) tuvo el honor de recibir el encargo de organizar el sexto congreso internacional (A Coruña, 2002) y la publicación de las actas (López Poza, 2004b). Esta asociación internacional también patrocina publicaciones, como la revista Emblematica (publicada en New York por Scholar Press desde 1986) y monografías especializadas que han supuesto avances importantes en el conocimiento de la materia.

En España, la Sociedad Española de Emblemática <http://www.emblematica.es/> convoca congresos cada dos años, lo que también ha impulsado estos estudios en el ámbito español, desde que en 1991 promovió su creación Santiago Sebastián. Puede consultarse su página web con noticia de todas las publicaciones que se han generado de los congresos y la revista que ahora patrocina: Imago $^{3}$. Otra revista, especializada en este caso en Emblemática general, Onomástica y Vexilología es Emblemata, patrocinada por la Cátedra «Barón de Valdeolivos», de la Institución «Fernando el Católico», de la Diputación de Zaragoza, que comenzó su publicación en 1995. Trabajos sobre emblemática y reseñas sobre publicaciones de esta materia pueden encontrarse también en la revista digital Janus ${ }^{4}$.

No es posible, en este corto espacio, atender con detalle a una revisión bibliográfica. Por otra parte, siguen estando vigentes los recursos impresos en formato convencional a los que aludía en mi trabajo presentado en Zaragoza en 1999, en el I Congreso Internacional de Emblemática General (López Poza, 2004a). Por tanto, remito a esa publicación, accesible en Internet en el repositorio de la Universidade da Coruña. Solo destacaré dos

3. Imago. Revista de Emblemática y Cultura Visual <http://ojs.uv.es/index.php/IMAGO/>

4. Janus. Estudios sobre el Siglo de Oro <http://www.janusdigital.es> 
grandes proyectos no incluidos allí que han ofrecido recientemente interesantes resultados:

El proyecto Mundus Symbolicus, de El Colegio de Michoacán (México), iniciado en 1987 bajo la dirección de Eloy Gómez, con la colaboración de Bárbara Skinfill Nogal. En 2006 la dirección pasó a Rosa Lucas. Como es sabido, el repertorio o enciclopedia de empresas de Filippo Picinelli (16041686) que tuvo enorme influencia en la literatura, las fiestas civiles y religiosas y el arte en los siglos xvII y xvIII, escrito originariamente en italiano como Mondo Simbolico (1653) y ampliado y traducido al latín por otro agustino (Agustin Erath) con el título de Mundus Symbolicus, llegó a alcanzar quince ediciones ${ }^{5}$. Ninguna de ellas en español. De los 25 libros que componen la obra, el equipo de El Colegio de Michoacán ha realizado en estos años la traducción al español desde la versión latina, de diez libros, publicados en siete volúmenes: 1, 2, 3, 4, 7 11 y 13:

\begin{tabular}{|c|c|l|}
\hline Volumen & Libros & \multicolumn{1}{|c|}{ Título datos edición } \\
\hline 1 & I & $\begin{array}{l}\text { Libro I: Los cuerpos celestes. Traducción de Eloy Gómez Bravo, introducción de Herón } \\
\text { Pérez y Carlos Herrejón, 1997. }\end{array}$ \\
\hline 2 & II & $\begin{array}{l}\text { Libro II: Los cuatro elementos. Traducción de Eloy Gómez Bravo y Rosa Lucas González, } \\
\text { introducción de Eloy Gómez Bravo, 1999 }\end{array}$ \\
\hline 3 & III & $\begin{array}{l}\text { Libro III. Primera parte: Dioses, héroes y hombres de la Antigüedad Clásica. Traducción de } \\
\text { Rosa Lucas González, introducción de E. Gabriel Sánchez Barragán, 2013 }\end{array}$ \\
\hline 4 & IV & $\begin{array}{l}\text { Libro IV. Las aves y sus propiedades. Traducción de Eloy Gómez Bravo, introducción de } \\
\text { Bárbara Skinfill, 2012 }\end{array}$ \\
\hline 7 & VII-VIII & $\begin{array}{l}\text { Libro VII. Serpientes y animales venenosos. Traducción de Rosa Lucas, introducción de } \\
\text { Jaime Cuadriello, 1999 } \\
\text { Libro VIII: Los insectos. Traducción de Eloy Gómez Bravo, introducción de Elena Es- } \\
\text { trada de Gerlero, 1999 }\end{array}$ \\
\hline 11 & XIII-XIV & $\begin{array}{l}\text { Libro XIII. Los metales. Traducción de Pascual Guzmán de Alba, introducción de Víctor } \\
\text { Mínguez, 2006 } \\
\text { Libro XIV. Los instrumentos eclesiásticos. Traducción e introducción de Alberto Carrillo } \\
\text { Cázares, 2006 }\end{array}$ \\
\hline 13 & XVII-XVIII & $\begin{array}{l}\text { Libro XVII. Los instrumentos mecánicos. Traducción de Rosa Lucas, introducción de } \\
\text { Agustín Jacinto Zavala, 2012 } \\
\text { Libro XVIII. Los instrumentos de juego. Traducción de Eloy Gómez Bravo, introducción } \\
\text { de Sagrario López Poza, 2012. }\end{array}$ \\
\hline
\end{tabular}

5. El Mundo Simbólico de Filippo Picinelli está dividido en dos orbes: uno celestial o natural, creado directamente por Dios (libros I-XIII), y otro terrenal o artificial, creado también por Dios solo que a través de la mano del hombre (libros XIV-XXV). Así en la primera parte de la obra se encuentran libros dedicados a los cuerpos celestes, los cuatro elementos, los dioses y hombres, los animales, las plantas, las gemas y los metales; y, en la segunda parte, se hallan libros consagrados a las partes de los edificios, a los instrumentos eclesiásticos, domésticos, mecánicos, matemáticos, musicales, agrícolas, entre otros. 
Fuentes de información y recursos de utilidad para el estudio e investigación de la Emblemática

Se prevé que muy pronto se publiquen los libros x, XXI, XXII, XXIII Y XXIV.

Otra publicación relevante reciente (2013) es: Pierio Valeriano, Jeroglíficos. Prólogo general y Libros $I-V$, edición y traducción al español realizada por Francisco José Talavera Esteso, catedrático de Filología Latina de la Universidad de Málaga, que dirige un proyecto de traducción de los 58 libros de que consta la obra ${ }^{6}$. Esta edición ofrece un estudio previo que ayuda a contextualizar la obra, a comprender la tradición en que se inserta y a conocer los métodos y procedimientos del humanista que la produjo; ofrece una edición crítica y una primera traducción al español con notas explicativas del Prólogo general y de los libros I-V de los Hieroglyphica de Pierio Valeriano Bolzani, con valiosas notas. Cierran el libro cuatro índices. También se reproducen las ilustraciones contenidas en la edición de Basilea de 1556 (Valeriano, 2013) ${ }^{7}$.

Tanto la obra de Pierio Valeriano (publicada por vez primera en 1556, aunque difundida manuscrita en parte desde $1529^{8}$ como la de Picinelli (1653) ${ }^{9}$ son instrumentos de capital importancia para los interesados en la emblemática, pues siguen siendo imprescindibles para descifrar textos, alegorías y pinturas que de otro modo no se comprenderían atinadamente. Ofrecen ayuda para la exégesis de los símbolos antiguos y brindan un corpus muy amplio de figuraciones alegóricas basadas en todo tipo de textos, y muy en especial los libros de emblemas.

También es digna de destacar como novedad la publicación de los emblemas de Adriano Junio traducidos al español por Beatriz Antón y Antonio Espigares (Junio, 2013). Esta traducción no sólo es la primera completa y fidedigna de los emblemas (62) y comentarios exegéticos realizados por el propio autor que se hace a partir de la editio princeps y de la edición ampliada de 1585. sino que además va precedida de un documentado y esclarecedor estudio preliminar, está ilustrada con profusas notas aclaratorias y ha sido enriquecida con útiles índices. Véanse para más detalles las reseñas de Victoria Eugenia Rodríguez y Gema Senés ${ }^{10}$, así como las de Manuel Mañas ${ }^{11}$ y Sagrario López Poza ${ }^{12}$.

Señaladas estas novedades en formato de publicación convencional, que no estaban en mi trabajo anterior citado, atenderé ahora a otros recursos que pueden resultar de utilidad.

\section{RECURSOS PARA EL ACCESO A FUENTES PRIMARIAS}

\section{Digitalización facsimilar de libros}

En muy pocos años se ha producido una digitalización masiva de fuentes primarias, llevada a cabo por iniciativa de las propias

6. Abarca grandes bloques: los animales cuadrúpedos (1-13), los reptiles (14-16), las aves (17-25), los insectos (26), y los animales acuáticos (27-31). Desde el libro 32 hasta el 36 desarrolla los valores simbólicos que se relacionan con el cuerpo humano y sus partes. En los libros 37-39 habla de los números significados mediante las diferentes posiciones de los dedos, de lo que se significa con los objetos relacionados con la escritura y de los campos del saber humano. Desde el libro 40 al 49 se ocupa de prendas y objetos que entran en la órbita de la actividad humana. El grupo homogéneo de los libros 50-58 trata de las diversas plantas.

7. Ver Reseña de Beatriz Antón en IMAGO Revista de Emblemática y Cultura Visual, 5 (2013), 139 -144. $<$ http://dx.doi.org/10.7203/imago.5.3061>

8. S. López Poza, 2008: 187-194.

9. S. López Poza, 2008: 199-200 y S. López Poza, 2012.

10. Imago, 5 (2013), 149-151.<http://dx.doi.org/10.7203/imago.5.3074>

11. Cuadernos de Filología Clásica. Estudios Latinos, 33.2 (2013), pp. 425-428. <http://revistas.ucm.es/index.php/ CFCL/issue/view/2472/showToc >

12. Janus, 3 (2014), 54-58, <http://www.janusdigital.es/articulo.htm?id=34>

IMAGO, NÚM. 6, 2013, 145-157 
bibliotecas, como es el caso de Gallica (Biblioteca Nacional de Francia), cuyas primeras digitalizaciones se remontan a 1992 y en 1997 cuando inició su programa "bibliothèque virtuelle de l'honnête homme». En 2000 se actualizó con una nueva versión y fue un ejemplo para muchas bibliotecas nacionales que seguían custodiando sus fondos con celo y poniendo obstáculos para el acceso a ellos. Igualmente admirable es la biblioteca estatal bávara (Bayerische Staatsbibliothek), cuyas ricas y variadas colecciones digitales de manuscritos e impresos ponen a disposición de infinidad de usuarios de todo el mundo reliquias y rarezas admirables, permitiendo así el acceso al conocimiento para quienes no pueden desplazarse a Múnich para verlas in situ. El Digitalisierungs Zentrum ha superado el millón de libros digitalizados y ofrecidos en Internet. Exactamente: 1.045.886 a comienzos de septiembre de 2014, momento de redacción de este escrito. Es una tarea meritoria a la que todo investigador ha de estar agradecido.

En 2005, se inició el proyecto Europeana, impulsado por la Comisión Europea de Sociedad de la Información y Medios, con una enorme dotación presupuestaria. Europeana es una biblioteca digital europea de acceso libre, que logró inaugurarse el 20 de noviembre de 2008 y reúne contribuciones ya digitalizadas de reconocidas instituciones culturales de los 27 países miembros de la Unión Europea. Es un punto común multilingüe de acceso al patrimonio cultural europeo. ${ }^{13}$ Sus fondos incluyen libros, películas, pinturas, periódicos, archivos sonoros, mapas, manuscritos y otros archivos (lo que hoy suele denominarse objetos digitales). Muchos libros de emblemas digitalizados y sus diferentes ediciones pueden hallarse a través de este portal.
En España, para cumplir las «Recomendaciones de 2006 del Consejo de Europa sobre la digitalización, la accesibilidad en línea del material cultural y la conservación digital ${ }^{14}$, se creó Hispana ${ }^{15}$, un directorio y recolector de recursos digitales español de importancia y muy poco conocido. Hispana reúne las colecciones digitales de archivos, bibliotecas y museos españoles y cumple en relación a los repositorios digitales españoles funciones análogas a las de Europeana en relación a los repositorios europeos, es decir, constituye un agregador de contenidos de las bases de datos de colecciones digitales. Hispana también incorpora los contenidos de CER.ES, el catálogo colectivo de la Red Digital de Colecciones de Museos de España.

The Internet Archive es una biblioteca digital y una organización sin ánimo de lucro destinada a dar "acceso universal a todo el conocimiento". Proporciona almacenamiento permanente y acceso gratuito a colecciones de materiales digitalizados: páginas web, música, vídeo y cerca de tres millones de libros. "Internet Archive» fue fundado por Brewster Kahle el 1996 y tiene su base en San Francisco, California, EE.UU y filiales en otros sitios. Además de su función ya dicha, "Internet Archive» es una organización activista, que defiende una Internet libre y abierta. En 1999 la organización dio un salto cualitativo. Recibe donaciones muy importantes y su contenido se replica en la Biblioteca de Alejandría. El grupo se ocupa de la popular Wayback Machine, un archivo de 364.000 millones de páginas web, diseñado para mostrar cómo eran las páginas web en el pasado reciente. En octubre de 2013, el grupo anunciaba que había alcanzado el almacenamiento de más de 10 petabytes (10.000.000 de gigabytes) de información. Ofrece digitalización de muchos libros de emblemas.

13. <http://www.europeana.eu/>

14. Publicadas en el Diario Oficial de la Unión Europea de 24 de agosto 2006.

15. <http://hispana.mcu.es> 
Fuentes de información y recursos de utilidad para el estudio e investigación de la Emblemática

Google books es otro lugar donde podemos encontrar acceso directo a libros de emblemas (o a través de la biblioteca que permitió la digitalización a Google). Hay una rica colección digitalizada de la Biblioteca Histórica Marqués de Valdecilla, del fondo antiguo de la Biblioteca de la Universidad Complutense en Madrid (46 libros) <http:// biblioteca.ucm.es/historica>

Otras bibliotecas que han digitalizado importantes colecciones de libros de emblemas y las hacen accesibles de forma gratuita en Internet son:

- Herzog August Bibliothek, de WolfenBüttel (463 libros de emblemas o similares) <http://www.hab.de/en/home/ research/projects/emblematica-online.html>

- Biblioteca Emblematica de la Universidad de Bergamo: <http://dinamico.unibg.it/ cav/emblematica/login.htm $>$ El archivo incluye un corpus de 372 volúmenes de libros de emblemas y empresas en formato digital de los años 1500 a la década de 1820. La base de datos permite búsqueda simple y avanzada de la información bibliográfica y ofrece las obras en formato digital facsimilar. El acceso requiere inscribirse mediante una petición por correo electrónico. La indexación es mínima, pero es muy importante el número de libros que tienen, procedentes de bibliotecas muy poco conocidas.

- La bilioteca de la Universidad de Pennsylvania ofrece también en The English Emblem Book Project, la digitalización de 10 libros de emblemas ingleses. <http://www.libraries.psu.edu/psul/ digital/emblem/books.html>

- Durante 2013 se ha incrementado mucho el número de libros digitalizados en la Biblioteca Digital Hispánica (entre ellos, cuatro o cinco docenas de libros de emblemas o afines) <http://www.bne.es/es/Catalogos/ BibliotecaDigitalHispanica/Inicio/>.
- Un recurso bastante antiguo pero que sigue siendo útil es el portal $M A$ TEO (Universidad de Mannheim, Alemania). Entre los recursos que ofrecen, está CAMENA (= Corpus Automatum Manhemiense Electorum Neolatinitatis Auctorum), en que podemos hallar un apartado dedicado a Fabulae; Symbola; Adagia; Exempla. Encontramos edición de los Hieroglyphica de Pierio Valeriano, así como un apartado útil de Historia; Geographia; Heraldica; Genealogia

De interés puede resultar también:

- RAA Repertorivm Alborvm Amicorvm, que ofrece un repertorio de este tipo de libros manuscritos, autógrafos de ejemplares de album amicorum (libro de los amigos, también Stammbuch alemán) que eran una especie de cuadernos de autógrafos recogidos por los estudiantes de los siglos XVI y XVII de Alemania o los Países Bajos, mientras iban de universidad en universidad. A veces hay escudos heráldicos, emblemas, empresas... La RAA facilita la localización de estos ejemplares únicos, muy útiles a veces para estudios genealógicos <http:// www.raa.phil.uni-erlangen.de/index.shtml>.

\section{Buscadores, metabuscadores, portales especializados}

El resultado de estas posibilidades de consulta es lo más importante que ha ocurrido en los últimos años no solo para mejorar el conocimiento de los libros de emblemas impresos o manuscritos (que se ofrecen digitalizados), sino también de objetos procedentes de museos que nos permiten conocer la emblemática aplicada, como se ha dado en llamar, en objetos de todo tipo: meda- 
llas, piezas de mayólica, joyas, ropajes, escudos, retratos grabados y pintados, etc. El conocimiento, pues, de todas las modalidades emblemáticas pasa hoy por desarrollar habilidades de consulta a través de Internet de los muchos recursos que se han puesto a nuestra disposición.

Para ello hay metabuscadores que ayudan a localizar las fuentes primarias que queremos encontrar, e incluso recuperar sólo obras reproducidas en formato digital, si así lo indica quien busca, como por ejemplo el metabuscador KIT (Karlsruhe Institute of Technology), que organiza la información y proporciona una ayuda muy importante a la investigación.

El SIELAE (Seminario Interdisciplinar para el estudio de la Literatura Áurea Española) de la Universidade da Coruña ofrece desde abril de 2006 el catálogo DEBOW: Catálogo de ediciones digitales de libros de emblemas y obras afines accesibles en Internet / DEBOW (Digital Emblem Books on Web), realizado por mi y por Sandra $\mathrm{M}^{\mathrm{a}}$ Fernández Vales, que ya va por la quinta edición (julio de 2013) y que contiene 1.266 registros de ediciones de libros de emblemas u obras afines en formato digital, con uno o más ejemplares disponibles en Internet, con los enlaces correspondientes para un acceso directo. El catálogo, que proporciona enlace a 1.934 ejemplares de libros de emblemas en formato digital, está accesible en Internet en formato PDF (ocupa 191 páginas $^{16}$ ). En octubre de 2013 incluimos todas esas fichas y otras más (las producidas después de julio de ese año en una nueva base de datos con aplicación de consulta y administración en el portal de BIDISO $^{17}$, que permite búsquedas simples o avanzadas y nos da la posibilidad de alimentar la base de datos continuamente según conocemos las digitalizaciones de ejemplares. La creación de DEBOW fue elogiada por The Society for Emblem Studies ${ }^{18}$ por el tiempo que ahorra a los investigadores en la realización de búsquedas de libros de emblemas en Internet.

\section{Publicaciones electrónicas enrique-} cidas con bases de datos de análisis, indexación, edición con transcripción y marcación de los textos, etc.

Aparte de las búsquedas en bibliotecas, portales, metabuscadores o a través del Catálogo DEBOW, las bibliotecas digitales especializadas en emblemática han supuesto un impulso impresionante para el conocimiento de los libros de emblemas.

La primera biblioteca digital de libros de emblemas accesible en Internet fue la de nuestro grupo, integrada ahora en el portal BIDISO. Los trabajos se iniciaron en 1992 y en 1996 se hizo accesible la digitalización, transcripción parcial y datos de análisis de una selección de 27 libros de emblemas españoles de los siglos XVI y XVII <http:// www.bidiso.es/cicyt/obras.html>. En 1999 se amplió el proyecto a 6 libros de emblemas escritos en otras lenguas y traducidos al español. Son dos bibliotecas digitales pioneras en el análisis experto de libros de emblemas: Biblioteca digital de emblemática hispánica y Biblioteca Digital de Libros de Emblemas Traducidos ${ }^{19}$. Aun siento primitivas, estas bases de datos tienen muchísima información útil y siguen teniendo muchos usuarios. Permiten búsquedas por palabras del mote, se ofrece transcripción y traducción de los motes, puede buscarse por motivos de las imágenes y se da su significado, proporciona

16. <http://www.bidiso.es/emblematica/CatalogoDEBOW.pdf>

17. <http://debow.bidiso.es/>

18. Society for Emblem Studies Newsletter, number 48, january 2011.

19. Ver López Poza, Sagrario y Ángeles Saavedra Places, 2014. 
Fuentes de información y recursos de utilidad para el estudio e investigación de la Emblemática

los epigramas transcritos y el tipo de estrofa, incluye un resumen transcrito de la glosa o declaración del emblema, incluye lista de citas e índices onomásticos: <http://www. bidiso.es/estaticas/ver.htm?id=4>

Un recurso también antiguo, pero que sigue siendo de gran utilidad es Alciato's Book of Emblems. The Memorial Web Edition in Latin and English. Ofrece el texto de los motes y epigramas transcritos y las picturae de algunas ediciones de la obra de Alciato, así como algunos comentarios. Han ido incorporando enlaces a la biblioteca digital Alciato de Glasgow y otros sitios. El proyecto lo inició William Barker, del departamento de inglés de la Memorial University en Canadá. Han ido enriqueciendo el texto con marcación posteriormente. Fue la primera aplicación que permitía ver de un golpe las picturae juntas de los emblemas de la obra de Alciato y siguen siendo muy útiles los textos de introducción, bibliografía, etc.

El Emblem Project Utrecht. Dutch Love Emblems of the Seventeenth Century <http:// emblems.let.uu.nl/> fue una aportación extraordinaria al conocimiento sobre los libros de emblemas. El proyecto multidisciplinar se desarrolló entre 2003 y 2006 en la Universidad de Utrecht, dirigido por la profesora de literatura neerlandesa Els Stronk $y$ en el que participaron hasta noviembre de 2006 Peter Boot, H. Brandhorst, M. de Gruijter, D. Stiebral, H. van Baren, G. Huijing, J.A. Blans, y J. Tilstra. Por primera vez se ofrecía en Internet, en una biblioteca digital especializada, la digitalización completa de los libros seleccionados (27 libros de emblemas de amor holandeses, profanos o religiosos), y además brindaba transcripción completa de los textos, en lenguaje XML y con marcación TEI, índices y opciones diversas de búsqueda. Han codificado las imágenes con el sistema ICONCLASS, que permite búsquedas paralelas por un motivo iconográfico. Uno puede ver juntas solo todas las picturae, o concordancias, o todas las imágenes facsimilares, y una rica variedad de notas (Boot, 2004 y 2008).

El 2 de noviembre de 2006 se presentaba el Glasgow Emblem Digitisation Project, en la misma línea que el proyecto de Utrecht y que realizó un magnífico trabajo para la comunidad científica. Son tres las bases de datos que se crearon a partir de los libros de emblemas conservados en la magnífica Glasgow's Stirling Maxwell Collection, de la University of Glasgow ${ }^{20}$. Naturalmente, estas no son bases de datos cualesquiera, sino de expertos investigadores en varias áreas: emblemática, bibliografía, informática y sobre las obras concretas que incluyen las colecciones. Fueron precisos muchos años de paciente trabajo de análisis bibliográfico para determinar qué ediciones era oportuno y conveniente digitalizar y ofrecer y qué material debía acompañarlas. Las bibliotecas digitales que nos ofrece el Centre for Emblem Studies de Glasgow son:

French Emblems at Glasgow ${ }^{21}$, dirigida por la profesora de literatura francesa Alison Adams. El equipo ha digitalizado 27 libros de emblemas franceses del siglo XVI (a excepción de uno, del s. XVII). Ofrece muy buena información especializada sobre las obras, transcripción con marcación XMLTEI, empleo de codificación Iconclass para las imágenes y muy buenas posibilidades de lectura y búsquedas. La interfaz es sencilla, amigable e intuitiva. El usuario puede tener abierta a la vez la página facsimilar y la transcripción.

Italian Project ${ }^{22}$, que se inició con una beca Marie-Curie del italiano Donato Mansueto. Se presentó a la vez que French Em-

20. Reúne la colección de unos 2.000 volúmenes que pertenecieron a Sir William Stirling Maxwell (1818-1878), entre los que destacan los libros de emblemas.

21. French Embems at Glasgow: <http://www.emblems.arts.gla.ac.uk/french/>

22. The Study and Digitisation of Italian Emblems: <http://www.italianemblems.arts.gla.ac.uk>

IMAGO, NÚM. 6, 2013, I45-157 
blems at Glasgow, pero este proyecto quedó incompleto. Se digitalizó un corpus de 7 libros de emblemas y empresas de autores italianos del siglo XVI, y alguna de las obras ofrecidas está incompleta.

Con la misma interfaz, poco después se presentó Alciato at Glasgow ${ }^{23}$, proyecto dirigido por Alison Adams y Stephen Rawles ${ }^{24}$, de la Universidad de Glasgow, que ofrece 22 ediciones del Emblematum liber de Alciato, desde las dos de 1531 de Augsburgo hasta la de Padua de 1621. En esta última, a la colección completa de emblemas acompañan los comentarios de Mignault, Sánchez de las Brozas, Pignorius y Thuilius. Alciato at Glasgow ofrece ediciones en el latín original, francés, alemán, italiano y español. Es una herramienta de primer orden para el investigador sobre emblemática.

Todavía en la década de los 90 del siglo pasado, para consultar una edición del libro de emblemas de Alciato había que tener la suerte de que una biblioteca cercana tuviera un ejemplar, o viajar a donde lo tuvieran, y lo más frecuente era encargar microfilms de las ediciones que nos interesaran después de hacer una ardua búsqueda para saber qué ediciones existían y en qué bibliotecas se custodiaban. No podíamos ni siquiera soñar que, desde nuestra casa, por medio de nuestro ordenador conectado a Internet, íbamos a poder consultar ja la vez! las principales ediciones de esta obra tan importante, y poder comprobar cómo va creciendo, desde los 104 emblemas iniciales (no todos ilustrados) hasta los 212 que conforman la versión definitiva. En los proyectos de Glasgow tenemos acceso a la digitalización completa y análisis de 27 ediciones de la obra de Alciato (pues a la base de datos de Alciato -que ofrece 22- se suman otras ediciones de la colección French Emblem). Todas estas ediciones no han sido elegidas sin más, sino que son las que presentan cambios o aspectos relevantes que las distinguen.

El beneficio para la investigación que aportan estos proyectos es inconmensurable.

Entre las bibliotecas digitales especializadas en emblemática, está el proyecto Emblematica Online ${ }^{25}$ que se inició con la digitalización de una selección de la importante colección de libros de emblemas que se conserva en la biblioteca universitaria de la Universidad de Illinois (más de 700 libros). En principio, el interés era la digitalización de los 56 libros de emblemas alemanes de la colección. Luego se incrementó con análisis experto y la creación del Open Emblem Portal. El proyecto lo dirige la norteamericana Mara Wade, profesora de literatura germana en la University of Illinois at UrbanaChampaign, e integra colecciones de emblemas de esa universidad con los de la Herzog August Bibliothek Wolfenbüttel (Alemania) <http://emblematica.grainger.illinois. edu>. El Open Emblem Portal pretende una federación de bibliotecas digitales de libros de emblemas, pues las que han empleado metadatos convencionales en sus registros (Utrecht, Glasgow y bibliotecas alemanas) permiten que sean recuperados en las búsquedas que se efectúen en el Open Emblem Portal, lo cual posibilita que se obtenga mucha información en las consultas. Aun así, la interfaz es menos "amigable" que las citadas.

Menos especializada en emblemática, pero interesante por contener alguna obra de interés para estos estudios, en formato digital con transcripción y marcación interna, es Bivio Biblioteca Virtuale on-line ${ }^{26}$. En ella podemos encontrar el Dialogo dell'imprese militari et amorose, edición de Lyon, Guglielmo Rouillio, 1574 y tres ediciones de la Ico-

23. Alciato at Glasgow: <http://www.emblems.arts.gla.ac.uk/alciato/>

24. Con la colaboración de Brian Aitken, Graeme Cannon, Joanna Royle, Gillian Smith, David Weston y las importantes contribuciones de Denis Drysdall y Mason Tung.

25. Emblematica online: <http://emblematica.grainger.illinois.edu/projectHistory.html>

26. BIVIO. Biblioteca Virtuale on-line. Testi e immagine dell'umanesimo e del Rinascimento <http://bivio.filosofia.sns.it/> 
Fuentes de información y recursos de utilidad para el estudio e investigación de la Emblemática

nologia de Ripa en italiano (de 1593, 1603 y 1611$)$.

De utilidad también es una base de datos accesible en Internet desde la primavera de 2014, patrocinada por el Centre d'Etudes Supérieures de Civilisation Médiévale con el soporte informático de la Université de Poitiers «DEVISE. Emblématique et héraldique à la fin du Moyen Age» <http://base-devise. edel.univ-poitiers.fr/index.php>. El núcleo de la base de datos procede de la tesis doctoral de Laurent Hablot: La devise, mise en signe du prince, mise en scène du pouvoir. Les devises et l'emblématique des princes en Europe à la fin du Moyen Age, defendida en 2001, dirigida por Michel Pastoureau y Martin Aurell. El objetivo manifestado es ir engrosando el corpus con todas las divisas posibles europeas de la Baja Edad Media y el Renacimiento (13501550). El proyecto invita a la colaboración y contribuciones de investigadores externos.

\section{Otros recursos de interés centrados en la imagen}

Arkyves $^{27}$ es una colección de fuentes para el estudio de la Historia de la Cultura, que convenientemente gestionadas en bases de datos, se ofrecen a un usuario que se inscriba y pague una cuota de acceso (que puede ser de unas horas a meses o años). Lo que nos interesa es la base de datos de imágenes, que permite búsquedas bien por conceptos verbales o a través de las ayudas que ofrece el sistema Iconclass. Abarca objetos digitales diversos en el formato y el tiempo (desde manuscritos medievales, imágenes de capitales iluminadas, etc. a pinturas, emblemas, grabados de distintas épocas, etc.). Las lenguas en que pueden efectuarse las búsquedas son inglés, alemán, francés e italiano. Están en proceso finés, portugués, polaco, español, alemán y chino.
ICONCLASS es un sistema de clasificación de imágenes, diseñado para las artes plásticas y la iconografía. Es la herramienta más extensamente utilizada para la descripción y recuperación de sujetos u objetos representados en imágenes (obras de arte, ilustraciones de libros, fotografías, etc. La usan los museos y en ocasiones bibliotecas digitales. Los proyectos descriptos (Utrecht, Glasgow, Emblematica online) también emplean este sistema para la clasificación de elementos iconográficos.

El Google Art Project <https://www. google.com/culturalinstitute/project/artproject> es también un recurso que conviene tener en cuenta, sobre todo por los especialistas en Historia del Arte. Ofrece imágenes en alta resolución de obras de arte expuestas en varios museos del mundo, lo que permite ver con detalles inusitados hasta ahora pinturas y otros objetos artísticos. A veces podemos detectar una pintura que incluye emblemas o divisas, un objeto de mayólica o un bordado que nos da información inaccesible hasta ahora. El proyecto fue puesto en servicio por Google el 1 de febrero de 2011 con 1.061 obras de diecisiete museos, entre los que se encuentran el Tate Britain de Londres, el Museo Metropolitano de Arte de Nueva York, y la Galería Uffizi de Florencia. La función de exploración de los museos se sirve de la misma tecnología utilizada por Google Street View. Aunque todas las obras se muestran en alta resolución, cada una de las diecisiete instituciones intervinientes al iniciarse el proyecto dispuso una de sus obras maestras para ser fotografiada y mostrada en el sitio mediante imágenes de 7.000 megapixeles. 


\section{RECURSOS PARA EL ACCESO A FUENTES SECUNDARIAS}

Las fuentes secundarias están también mucho más accesibles ahora, gracias a bases de datos bibliográficas y a hemerotecas digitales, como por ejemplo Dialnet ${ }^{28}$, segundo portal de contenidos bibliográficos del mundo y la mayor hemeroteca de artículos científicos hispanos en Internet, de acceso libre.

El grupo de investigación sobre Literatura Emblemática Hispánica de la Universidade da Coruña, que luego formó el SIELAE ${ }^{29}$, ofrece desde Septiembre de 1996 bibliografía específica sobre emblemática en las categorías de repertorios, ediciones o estudios ${ }^{30}$. Ahora tiene también una forma de acceso integrado en el portal BIDISO (Biblioteca Digital Siglo de Oro) ${ }^{31}$, donde en la sección de bibliografía especializada del portal se puede acceder a una aplicación de búsqueda en una base de datos, recuperar las fichas, seleccionar las que interesen al que consulta y exportarlas en formato PDF si lo considera oportuno para elaborar así una bibliografía personalizada sobre los intereses del usuario. El número de referencias bibliográficas relacionadas con la emblemática que contiene esa base de datos en el momento de redactar este trabajo es 3.040.

En Studiolum ${ }^{32}$ también encontramos Bibliografía Emblemática Hispánica una base de datos de bibliografía sobre emblemática, aunque comenzó a decaer en el 2011 . En el momento de redactar este trabajo no hallamos más que dos fichas de 2012 y ninguna de 2013 ni de 2014.

Es fácil prever, por todo lo dicho, que veremos en los próximos años un incremento notable de los estudios sobre emblemática, mejoras en la recuperación de ediciones desconocidas o recuperación de ejemplares perdidos, y desde luego, ediciones de textos con marcación que harán más fácil realizar búsquedas, recuperar fragmentos de texto o cadenas textuales, y mejorar relaciones semánticas. Son grandes las esperanzas en este sentido.

\section{BIBLIOGRAFÍA}

Andreas Alciatus, 1 [1985]. Andreas Alciatus, 1. The Latin Emblems, Indexes and Lists (Index Emblematicus), ed. Peter M. Daly y Virginia W. Callahan, Toronto, University of Toronto Press.

Воот, P. [2004]. "Accessing emblems using XML. Digitisation Practice at the Emblem Project Utrecht», en López Poza, Sagrario (ed.), Florilegio de Estudios de Emblematica. A Florilegium of Studies on Emblematics. Proceedings of the 6th International Conference of the Society for Emblem Studies, A Coruña, 2002. Ferrol 2004. Pp. 191-197.

Воот, P. [2008]. «Facilitating Emblem Research at the Emblem Project Utrecht", en: Con parola brieve e con figura. Emblemi e imprese fra antico e moderno, Lina Bolzoni, Silvia Volterrani (eds.), Pisa, Edizioni della Normale 2008 p. 619-630.

DalY, P. M. [1988]. «The Union Catalogue of Emblem Books Project and the Corpus Librorum Emblematum», Emblematica, 3, 121-33.

\footnotetext{
28. DIALNET <http://dialnet.unirioja.es/> sielae $>$

30. <http://www.bidiso.es/emblematica/>

31. BIDISo <http://www.bidiso.es/bidisob/principal.htm?global=true $>$

32. Studiolum <http://www.emblematica.com/es/>
}

29. SIELAE (Seminario Interdisciplinar para el Estudio de la Literatura Áurea Española) <http://www.bidiso.es/ 
Fuentes de información y recursos de utilidad para el estudio e investigación de la Emblemática

Heckscher, W. S. [1989]. The Princeton Alciati Companion: a Glossary of Neo-Latin Words and Phrases used by Andrea Alciati and the Emblem Book Writers of his Time, including a bibliography of secondary sources relevant to the study of Alciati's emblems, New York, Garland.

Junio, A. [2013]. Adriano Junio. Emblemas. Estudio Introductorio de Beatriz Antón. Traducción, notas e índices de Beatriz Antón y Antonio Espigares. Libros Pórtico, Zaragoza.

López PozA, S. [2004a]. "La proyección emblemática en la Literatura», en Actas del I Congreso Internacional de Emblemática General, Guillermo Redondo Veintemillas, Alberto Montaner Frutos, María Cruz García López (Eds.), Zaragoza, Institución "Fernando el Católico» (C. S. I. C.), Excma. Diputación de Zaragoza Zaragoza, 2004, vol. III, pp. 1875-1907 <http:// hdl.handle.net/2183/11657>.

López PozA, S. (ed.) [2004b]. Florilegio de estudios emblemáticos $=$ A Florilegium of Studies on Emblematics. Actas del VI Congreso Internacional de Emblemática de The Society for Emblem Studies, celebrado en A Coruña, 2002. La Coruña, Ediciones de la Sociedad de Cultura Valle-Inclán, SIELAE.

López PozA, S. [2008]. "Sabiduría cifrada en el Siglo de Oro: las enciclopedias de Hieroglyphica y figuraciones alegóricas». En: Edad de Oro, XXVII, 167-200. <http:// ruc.udc.es/handle/2183/11767>.
LÓPez PozA, S. [2012]. "El repertorio de Picinelli: de Codex excerptorius a Mondo simbolico. Introducción», En: Filippo Picinelli, El Mundo Simbólico. Los instrumentos mecánicos. Los instrumentos de juego (libros XVII-XVIII), editoras: Rosa Lucas González, Bárbara Skinfill Nogal; con la colaboración de Jorge Arreola Barraza; traductores: Rosa Lucas González (Los instrumentos mecánicos), Eloy Gómez Bravo (Los instrumentos de juego), Zamora, Michoacán (México) : El Colegio de Michoacán, Fideicomiso Teixidor, pp. 31-50. http://ruc.udc.es/handle/2183/11766.

López Poza, S. y Á. SaAvedra Places [2014]. «Recursos digitales ofrecidos por el SIELAE para el estudio del Siglo de Oro. Creación, gestión y evolución de BIDISO», en Humanidades Digitales: desafíos, logros y perspectivas de futuro, Sagrario López Poza y Nieves Pena Sueiro (editoras), Janus [en línea], Anexo 1 (2014), 285-303, publicado el 11/04/2014, consultado el 14/04/2014. URL: http:// Www.janusdigital.es/anexos/contribucion.htm?id=27.

Tung, M. [1989]. "Towards a new Census of Alciati's Editions'», Emblematica 4, 135 176.

Valeriano, P. [2013]. Jeroglíficos. Prólogo General y Libros I-V. Ed. a cargo de José Talavera Esteso. Prólogo de Sagrario López Poza. Alcañiz-Madrid, Instituto de Estudios Humanísticos, CSIC, 2013. 
